Sharif University of Technology
Scientia Iranica
SCIENTIA
I RAN I CA
http://scientiairanica.sharif.edu

\title{
The use of neural networks for predicting the factor of safety of soil against liquefaction
}

\author{
Y. Erzin* and Y. Tuskan \\ Department of Civil Engineering, Faculty of Engineering, Manisa Celal Bayar University, 45140 Manisa, Turkey.
}

Received 17 February 2016; received in revised form 27 November 2017; accepted 29 April 2018

\author{
KEYWORDS \\ Artificial neural \\ networks; \\ Factor of safety; \\ Liquefaction potential; \\ Multiple regression; \\ Simplified method.
}

\begin{abstract}
In this paper, the Factor of Safety (FS) values of soil against liquefaction was investigated by means of Artificial Neural Network (ANN) and Multiple Regression (MR). To achieve this, two earthquake parameters, namely earthquake magnitude $\left(M_{w}\right)$ and horizontal peak ground acceleration $\left(a_{\max }\right)$, and six soil properties, namely Standard Penetration Test Number (SPT-N), saturated unit weight $\left(\gamma_{s a t}\right)$, natural unit weight $\left(\gamma_{n}\right)$, Fines Content (FC), the depth of Ground Water Level (GWL), and the depth of the soil (d), varied in the liquefaction analysis; then, the FS value was calculated by the simplified method for each case by using the Excel program developed and utilized in the simulation of the feed-forward ANN model with backpropagation algorithm and the MR model. The FS values predicted by both ANN and MR models were compared with those calculated by the simplified method. In addition, five different performance indices were used to evaluate the predictabilities of the models developed. These performance indices indicated that the ANN models were superior to the MR model in terms of predicting the FS value of the soil. (C) 2019 Sharif University of Technology. All rights reserved.
\end{abstract}

\section{Introduction}

Liquefaction is one of the significant, remarkable, and complex topics in geotechnical engineering [1]. Foundations and substructures were controlled by the generation of liquefaction assessment caused by the strength reduction of the soil and the inability of soil deposit [2,3]. Major earthquakes (e.g., the 1964 Alaska, 1964 Niigata, 1989 Loma-Prieta, and 1995 HyogokenNambu) have illustrated the devastating effects of soil liquefaction.

The estimation and assessment of liquefaction is an essential component of the earthquake-resistant modeling of structures on liquefiable soils. Liquefaction potential gains a quantitative form in terms of Factor

\footnotetext{
*. Corresponding author. Tel.: +90236 2012312;

Fax: +902362412143

E-mail address: yusuf.erzin@cbu.edu.tr (Y. Erzin).
}

of safety (FS) at a certain depth of a site. A simplified procedure for assessing the liquefaction resistance of soils was developed by Seed and Idriss [2] to resist seismic demand. While the Cyclic Resistance Ratio (CRR) indicates the liquefaction resistance, seismic demand is denoted by Cyclic Stress Ratio (CSR). Several in-situ tests, namely Standard Penetration Test (SPT), Conic Penetration Test (CPT), Becker Penetration Test (BPT), and shear wave velocity (Vs) test, can be performed to obtain FS value of a soil layer [4]. Among them, liquefaction resistance of soils is generally and easily evaluated by a commonly used method, i.e., a simplified empirical procedure based on SPT $[2,4]$. A soil layer with FS value smaller than 1 is usually categorized as liquefiable, and that with FS value greater than 1 is categorized as non-liquefiable [5].

In this study, the developed Excel program [6] was utilized to calculate the FS values of the soil subjected to earthquake forces by using the simplified method developed by Seed and Idriss [2]. Two earthquake parameters, namely earthquake magnitude $\left(M_{w}\right)$ and 
horizontal peak ground acceleration $\left(a_{\max }\right)$, and six soil properties, namely Standard Penetration Test Number (SPT-N), saturated unit weight $\left(\gamma_{\text {sat }}\right)$, natural unit weight $\left(\gamma_{n}\right)$, Fines Content (FC), the depth of Ground Water Level (GWL), and the depth of the soil $(d)$, varied during the liquefaction analyses. Then, the FS values were calculated for each case by using the Excel program [6] developed to generate both models.

\section{Artificial neural networks}

Artificial Neural Networks (ANNs) are diagnostic procedures that imitate the behavior of the brain functions and human nervous system [7]. ANN is an information system that aims to provide capabilities like those of the human brain that resemble systems of learning, association, classification, making generalizations, estimation, and optimization [8]. The limitations of various numerical modeling techniques and failures of many mathematical models in investigating the highly non-linear behavior of soils are also considered; therefore, these techniques and models are too complex, time-consuming, and impractical to be applicable as geotechnical approaches.

Generally, ANNs are divided into two major types: Feed-Forward (FF) and Recurrent (R). One of the most well-known FF-ANN is multilayer perceptron (MLP) neural network. An ANN architecture (Figure 1) is made up of an input layer, an output layer, and one or more hidden layers [9]. BackPropagation (BP) networks learn through continuing existence, and its characterization facilitated a wide range of its applications in civil engineering [10]. The accuracy of the model prediction is influenced by the number of hidden layers and neurons in the BP network [10]. Depending on the complexity of the problem and the size of the database, it is not a particular rule to define the optimal number of hidden neurons or the number [11]. Most accurate predictions

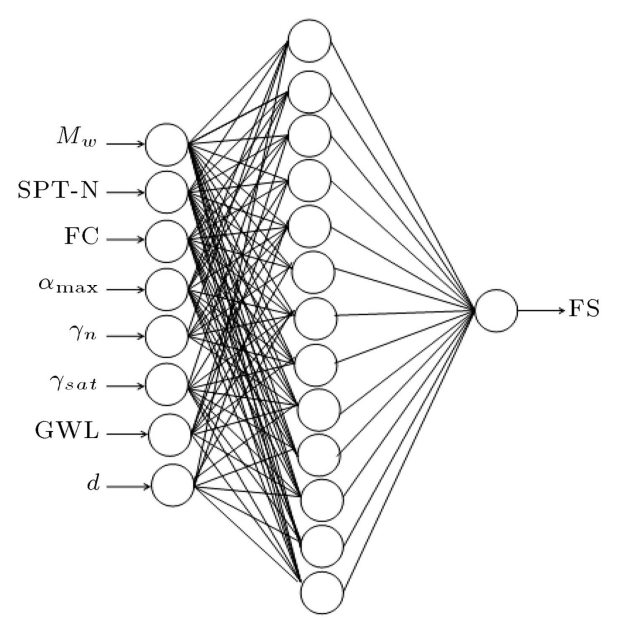

Figure 1. The ANN's architecture. are generally obtained with one hidden layer [10]. However, the successful selection of a sufficient number of neurons is presented under the feedback of these methods [12]. The input parameters are variables that influence the answers to this problem. Output parameters corresponding to the number of neurons in the output layer are the expected answers to the problem [10]. Neurons of the output layer communicate in the system of external environment provided that the output is properly configured [13]. MLP-ANN can be trained by different algorithms. As reported by several researchers [14-16], Levenberg-Marquardt (LM) training algorithms are employed for the networks. Finally, the network produces outputs for the given inputs. These outputs are finally compared with the targets that are the simulation results. Details of the simplified method [2] applied for calculating the FS values of the soil are presented in the following section.

\section{Calculation of the factor of safety value against liquefaction}

Liquefaction analysis must be carried out for highly liquefiable soil using possible earthquake prediction results. In the literature, many methods proposed for this purpose can be examined under the following titles: cyclic stress approach, cyclic deformation approach, energy absorption approach, and effective stress based approach [5,17]. Among these approaches, the cyclic stress approach was selected in this study due to its proximity to reality in the conditions of a seismically induced liquefaction failure. The cyclic stress approach, apparently first introduced by Seed and Idriss [2] and referred to as the simplified procedure, is still the most common procedure employed for standard seismic liquefaction evaluation. In this approach, both the Cyclic Strength Ratio (CSR) of soil formed by the earthquake and the Cyclic Resistance Ratio (CRR) excited in the soil deposit during an earthquake are computed. Then, the liquefaction assessment expressed in terms of the Factor of Safety (FS) against liquefaction is determined through the following equation:

$$
F S=(C R R / C S R) \times M S F,
$$

where MSF is the Magnitude Scaling Factor multiplied by CRR/CSR ratio during earthquake magnitude $\left(M_{w}\right.$ value of 7.5). Youd and Noble [18] recommended the use of the following equation for determining the MSF value as presented in Eq. (1):

$$
M S F=\frac{10^{2.24}}{M_{w}^{2.56}} .
$$

Cyclic Stress Ratio (CSR) presented in Eq. (1) denotes the seismic requirement caused by an earthquake. The CSR value can be evaluated by peak ground surface 
acceleration depending on ground motions of the selected site. In this study, CSR values were determined through the following equation proposed by Seed et al. [19]:

$$
C S R=0.65 \frac{\sigma_{v}}{\sigma_{v}^{\prime}} \frac{a_{\max }}{g} r_{d}
$$

where $\sigma_{v}$ is the total vertical stress, $\sigma_{v}^{\prime}$ is the effective vertical stress, $a_{\max }$ is the peak horizontal ground surface acceleration, $g$ is the acceleration of gravity, and $r_{d}$ is the stress reduction factor. A weighting factor of 0.65 was utilized to generate the $C S R$ formula [17]. The stress reduction factor, $r_{d}$, is calculated by Eq. (4) [20] as shown in Box I.

Cyclic Resistance Ratio (CRR) presented in Eq. (1) was determined by an equivalent clean sand SPT value, $\left(N_{1}\right)_{60 c s}$. Youd et al. [4] suggested the following CRR equation to approximate the modified CRR curve of Seed et al. [19] for the soil adjusted to $1.0 \mathrm{~atm}$. of effective overburden pressure for a moment magnitude of 7.5. In this study, CRR values were determined by the following equation:

$$
\begin{aligned}
C R R_{7.5}= & \frac{1}{34-\left(N_{1}\right)_{60 c s}}+\frac{\left(N_{1}\right)_{60 c s}}{135} \\
& +\frac{50}{\left[10\left(N_{1}\right)_{60 c s}+45\right]^{2}}-\frac{1}{200} .
\end{aligned}
$$

In this study, $\left(N_{1}\right)_{60 c s}$ value was determined by the following equation as suggested by Seed and Idriss [2]:

$$
\left(N_{1}\right)_{60 c s}=\alpha+\beta\left(N_{1}\right)_{60},
$$

where $\left(N_{1}\right)_{60}$ is the normalization of penetration resistance, and $\alpha$ and $\beta$ are the coefficients calculated through the equations given in Table 1 .

Seed and Idriss [2] proposed Eq. (8) to determine $\left(N_{1}\right)_{60}$ value. In this equation, $C_{N}$ is the overburden blow count correction, $C_{E}$ is the energy correction, $C_{R}$ is the drill rod length correction, $C_{B}$ is the borehole diameter correction, $C_{S}$ is the sampler liner correction, and $N_{m}$ is the measured standard penetration resistance.

$$
\left(N_{1}\right)_{60}=C_{N} C_{E} C_{B} C_{R} C_{S} N_{m} .
$$

In this study, $C_{B}$ value is taken as 1.00 assuming that
Table 1. Calculation of $\alpha$ and $\beta$ coefficients.

\begin{tabular}{llc}
\hline & Equation & $\begin{array}{c}\text { Equation } \\
\text { number }\end{array}$ \\
\hline$F C \leq 5 \%$ & $\alpha=0$ & $(7 \mathrm{a})$ \\
$5 \%<F C$ & $\alpha=\exp \left[1.76-\left(190 / F C^{2}\right)\right]$ & $(7 \mathrm{~b})$ \\
$F C \geq 35 \%$ & $\alpha=5.0$ & $(7 \mathrm{c})$ \\
$F C \leq 5 \%$ & $\beta=1.0$ & $(7 \mathrm{~d})$ \\
$5 \%<F C$ & $\beta=\left[0.99+\left[\left(F C^{1.5} / 1000\right)\right]\right.$ & $(7 \mathrm{e})$ \\
$F C \geq 35 \%$ & $\beta=1.2$ & $(7 \mathrm{f})$ \\
\hline
\end{tabular}

Table 2. Corrections made to SPT-N (modified from Skempton [22]) as listed by Robertson and Wride [23].

\begin{tabular}{cccc}
\hline Factor & $\begin{array}{c}\text { Equipment } \\
\text { variable }\end{array}$ & Term & Correction \\
\hline \multirow{4}{*}{ Rod length } & $<3 \mathrm{~m}$ & & 0.75 \\
& $3-4 \mathrm{~m}$ & & 0.80 \\
& $6-6 \mathrm{~m}$ & $C_{R}$ & 0.85 \\
& $10-30 \mathrm{~m}$ & & 0.95 \\
\hline
\end{tabular}

the borehole diameter is between $65 \mathrm{~mm}$ and $115 \mathrm{~mm}$, and $C_{S}$ is also taken as 1.00 due to liners [21]. $C_{R}$ values suggested by Skempton [22] and updated by Robertson and Wride [23] for a range of rod lengths are given in Table 2 . In this study, $C_{R}$ values were selected from this table. The SPT blow count was normalized to an overburden pressure of $100 \mathrm{kPa}$, as suggested by Kayen et al. [24]. Youd et al. [4] suggested that $C_{N}$ value must be bounded to a maximum value of 1.70 . In this study, $C_{N}$ value was calculated by the following equation [4]:

$$
C_{N}=\frac{2.2}{1.2+\frac{\sigma_{v 0}^{\prime}}{P_{0}}}
$$

where $\sigma_{v 0}^{\prime}$ is the effective overburden pressure, and $P_{0}$ is $100 \mathrm{kPa}$.

As mentioned earlier, the cyclic stress approach, referred to as the simplified procedure [2], is the most common procedure employed for standard seismic liquefaction evaluation. Therefore, this procedure [2] was used in this study during the liquefaction analysis. This procedure requires the computation of three terms:

$$
r_{d}=\frac{\left(1.000+0.4113 z^{0.5}+0.04052 z+0.001753 z^{1.5}\right)}{\left(1.000-0.4177 z^{0.5}+0.05729 z-0.006205 z^{1.5}+0.00121 z^{2}\right)},
$$

where $z$ is the depth in $\mathrm{m}$. 
(i) The Cyclic Stress Ratio (CSR) represented by Eq. (3);

(ii) The capacity of the soil to resist liquefaction, or Cyclic Resistance Ratio (CRR) represented by Eq. (5);

(iii) The Factor of Safety (FS) against liquefaction represented by Eq. (1).

As mentioned earlier, if FS value is smaller than 1, liquefaction may occur. The soil and earthquake parameters, namely the depth of the soil from ground surface $(d)$, SPT-N value, earthquake moment magnitude $\left(M_{w}\right)$, Fines Content $(\mathrm{FC})$, peak ground acceleration $\left(a_{\max }\right)$, the total and effective vertical stresses $\left(\sigma_{v 0}\right.$ and $\left.\sigma_{v 0}^{\prime}\right)$, and the depth of Ground Water Level (GWL) from the ground surface, were considered to be used in calculating CSR and CRR values. These eight parameters changed during the liquefaction analysis as follows: Firstly, the depth of the soil from ground surface $(d)$ was allowed to vary from $1.5 \mathrm{~m}$ to $19.5 \mathrm{~m}$ with an interval of $1.5 \mathrm{~m}$. Then, $M_{w}$ was allowed to vary from 4 to 8 with an interval of 2 for each $d$ value. The SPT-N value was then allowed to vary from 5 to 35 with the step of 10 for each $M_{w}$. Seed and Idriss [25] proposed an apparent increase of CRR, given by Eq. (5), with the increasing Fines Content (FC). Thus, the FC value of the soil for each SPT-N value changed from 5 to 50 with the step of 15. In the NCEER 1997 [26] liquefaction evaluation procedure, there are two instances where calculations involving the unit weight of the soils are performed. First, when the CSR of the soil for each depth is evaluated using Eq. (3), both $\sigma_{v 0}$ and $\sigma_{v 0}^{\prime}$ values at that point are required. Second, as mentioned earlier, when evaluating the liquefaction potential based on the results of SPT-N results, a correction factor, $C_{N}$, given by Eq. (9), is applied to correct the SPT-N value to an overburden pressure of $100 \mathrm{kPa}$, which requires $\sigma_{v 0}^{\prime}$ value at that point. In this study, to calculate $\sigma_{v 0}$ and $\sigma_{v 0}^{\prime}$ values for each depth, the saturated unit weight $\left(\gamma_{\text {sat }}\right)$ value of each FC varied in the range of 18,20 , and $22 \mathrm{kN} / \mathrm{m}^{3}$; the natural unit weight $\left(\gamma_{n}\right)$ value for each $\mathrm{FC}$ value varied in the range of 16,18 , and $20 \mathrm{kN} / \mathrm{m}^{3}$; the Ground Water Level value (GWL) from the ground surface was allowed to vary from 1 $\mathrm{m}$ to $9 \mathrm{~m}$ with the step of $4 \mathrm{~m}$ for each $M_{w}$. In a strong earthquake of ground conditions, even with a very high risk of liquefaction, the required horizontal ground surface acceleration to liquefaction occurrence must undergo $0.1 \mathrm{~g}$ [27]. Ishihara [28] suggested peak ground acceleration $\left(a_{\max }\right)=0.2 \mathrm{~g}$ at the beginning of liquefaction occurrence to evaluate the possibility of liquefaction-induced ground damage and, also, to determine the thickness of unliquefiable soil surface layer. Therefore, in this study, $a_{\max }$ value was allowed to vary from $0.1 \mathrm{~g}$ to $0.5 \mathrm{~g}$ with the step of 0.1 .
Finally, CSR, CRR, and FS values against liquefaction values were calculated for different soil and earthquake parameters by using Eqs. (2), (3), and (5), respectively, and by using the written Excel program [6].

\section{Artificial neural network model}

In this paper, an ANN model is constructed to estimate the Factor of Safety (FS) value of soil against liquefaction. In this model, the ANN is designed just to estimate the liquefaction assessment. In this model, the earthquake magnitude, $M_{w}$, horizontal peak ground acceleration, $a_{\max }$, the soil properties, namely saturated unit weight, $\gamma_{s a t}$, natural unit weight, $\gamma_{n}$, fines content, FC, the depth of the soil, $d$, and the depth of ground water level, GWL, are the input parameters, and the calculated FS value is the only output parameter. The parameters are scaled between 0 and 1 :

$$
x_{\mathrm{norm}}=\frac{\left(x-x_{\min }\right)}{\left(x_{\max }-x_{\min }\right)},
$$

where $x_{\text {norm }}$ and $x$ are the normalized and actual values, and $x_{\max }$ and $x_{\min }$ are the maximum and minimum values.

Generally, while developing the ANN model, the available data are separated into two subsets, i.e., a training set and an independent validation set, which may cause over-fitting of the model [29]. Over-fitting occurs mainly because of training of the network with too many epochs [30]. Consequently, the crossvalidation technique [31], considered as a significant procedure to avoid over-fitting [32], was utilized as a stopping criterion with three subgroups [33]. Usually, training and testing sets were processed by using the two-thirds of the data, and one-third was selected for validation [34]. However, the optimal model was achieved with a $20 \%$ division of the validation subset, and the remaining data were divided into $30 \%$ for testing and $70 \%$ for training. Thus, in this study, $56 \%$ (i.e., 3260 ), $24 \%$ (i.e., 1570 ), and $20 \%$ (i.e., 1308) of all data were randomly chosen and utilized for training, testing, and validation samples used in the development of the ANN model. The details of the parameters used for these three subsets are listed in Table 3. Based on Table 3, the datasets used in the study are found to have been unbiasedly selected. The data derived from several liquefaction assessments have identified that, even by using just one hidden layer, any complex function in a network can be solved. Consequently, in this paper, one hidden layer was chosen to make the ANN model. The fixation of the hidden neurons with the minimal error and the highest accuracy is yielded by using 13 hidden neurons in the optimal ANN model with a log-sigmoid transfer function in hidden and output layers. 
Table 3. Details of the parameters used for the training, testing, and validation of the ANN model developed.

\begin{tabular}{|c|c|c|c|c|c|c|c|}
\hline & $\begin{array}{l}\text { Data } \\
\text { type }\end{array}$ & $\begin{array}{c}\text { Number of } \\
\text { data }\end{array}$ & $\begin{array}{c}\text { Model } \\
\text { parameters }\end{array}$ & $\begin{array}{l}\text { Minimum } \\
\text { value }\end{array}$ & $\begin{array}{c}\text { Maximum } \\
\text { value }\end{array}$ & $\begin{array}{l}\text { Mean } \\
\text { value }\end{array}$ & $\begin{array}{l}\text { Standard } \\
\text { deviation }\end{array}$ \\
\hline \multirow{9}{*}{ Training set } & \multirow{8}{*}{ Input } & \multirow{8}{*}{3260} & $M_{w}$ & 4 & 8 & 5.88 & 1.57 \\
\hline & & & $a_{\max }\left(\mathrm{cm} / \mathrm{s}^{2}\right)$ & 0.1 & 0.5 & 0.30 & 0.16 \\
\hline & & & GWL (m) & 1 & 9 & 4.96 & 3.27 \\
\hline & & & $d(\mathrm{~m})$ & 1.5 & 19.5 & 10.37 & 5.65 \\
\hline & & & SPT-N & 5 & 35 & 19.13 & 10.63 \\
\hline & & & $\gamma_{n}\left(\mathrm{kN} / \mathrm{m}^{3}\right)$ & 16 & 20 & 17.36 & 1.49 \\
\hline & & & sat $\left(\mathrm{kN} / \mathrm{m}^{3}\right)$ & 18 & 22 & 20.70 & 1.48 \\
\hline & & & $F C(\%)$ & 5 & 50 & 27.39 & 16.76 \\
\hline & Output & & FS & 0.27 & 8.80 & 3.19 & 5.22 \\
\hline \multirow{9}{*}{ Testing set } & \multirow{8}{*}{ Input } & \multirow{8}{*}{1570} & $M_{w}$ & 4 & 8 & 6.43 & 1.62 \\
\hline & & & $a_{\max }\left(\mathrm{cm} / \mathrm{s}^{2}\right)$ & 0.1 & 0.5 & 0.3 & 0.163 \\
\hline & & & GWL (m) & 1 & 9 & 5.18 & 3.24 \\
\hline & & & $d(\mathrm{~m})$ & 1.5 & 19.5 & 11.02 & 6.74 \\
\hline & & & SPT-N & 5 & 35 & 2.62 & 1.43 \\
\hline & & & $\gamma_{n}\left(\mathrm{kN} / \mathrm{m}^{3}\right)$ & 16 & 20 & 17.34 & 1.49 \\
\hline & & & $\gamma_{\text {sat }}\left(\mathrm{kN} / \mathrm{m}^{3}\right)$ & 18 & 22 & 20.70 & 1.47 \\
\hline & & & $\mathrm{FC}(\%)$ & 5 & 50 & 27.57 & 17.25 \\
\hline & Output & & FS & 0.92 & 8.59 & 3.23 & 5.18 \\
\hline \multirow{9}{*}{ Validation set } & \multirow{8}{*}{ Input } & \multirow{8}{*}{1205} & $M_{w}$ & 4 & 8 & 6.21 & 1.67 \\
\hline & & & $a_{\max }\left(\mathrm{cm} / \mathrm{s}^{2}\right)$ & 0.1 & 0.5 & 0.29 & 0.17 \\
\hline & & & GWL (m) & 1 & 9 & 5.11 & 3.25 \\
\hline & & & $d(\mathrm{~m})$ & 1.5 & 19.5 & 10.99 & 5.09 \\
\hline & & & SPT-N & 5 & 35 & 19.60 & 11.04 \\
\hline & & & $\gamma_{n}\left(\mathrm{kN} / \mathrm{m}^{3}\right)$ & 16 & 20 & 17.44 & 1.54 \\
\hline & & & $\gamma_{\text {sat }}\left(\mathrm{kN} / \mathrm{m}^{3}\right)$ & 18 & 22 & 20.66 & 1.52 \\
\hline & & & $\mathrm{FC}(\%)$ & 5 & 50 & 27.74 & 16.83 \\
\hline & Output & & FS & 0.33 & 7.68 & 2.97 & 5.30 \\
\hline
\end{tabular}

\section{Multiple regression model}

Multiple Regression (MR) analysis was carried out to correlate the determined FS value of liquefaction potential with six soil parameters (i.e., $\gamma_{n}, \mathrm{FC}$, SPT$\mathrm{N}, \gamma_{s a t}$, GWL, and $\left.d\right)$ and two seismic parameters $\left(M_{w}\right.$ and $\left.a_{\max }\right)$. MR model yielded the stated equation:

$$
\begin{aligned}
F S= & 11.478-1.174 M_{w}+0.1125 S P T-N \\
& +0.027 F C-10.937 \alpha_{\max }-0.034 \gamma_{n}+0.02 \gamma_{\text {sat }} \\
& +0.082 G W L-0.064 d, \\
R^{2}= & 0.626
\end{aligned}
$$

where $a_{\max }$ is in $\mathrm{cm} / \mathrm{s}^{2}, \gamma_{n}$ and $\gamma_{s a t}$ are in $\mathrm{kN} / \mathrm{m}^{3}$, and $d$ and GWL are in $\mathrm{m}$.

\section{Results and discussion}

The plots of the comparison of FS values obtained by the ANN model with those computed by the simplified method [2] are shown in Figures 2 to 4 . These figures illustrate that the predicted FS values are found to be quite close to the computed FS values. These results indicate the overall good agreement between the ANN model and the simplified method [2]. Hence, FS value was predicted with acceptable accuracy based on the easily determined soil properties and seismic coefficient with the use of trained ANN values. 


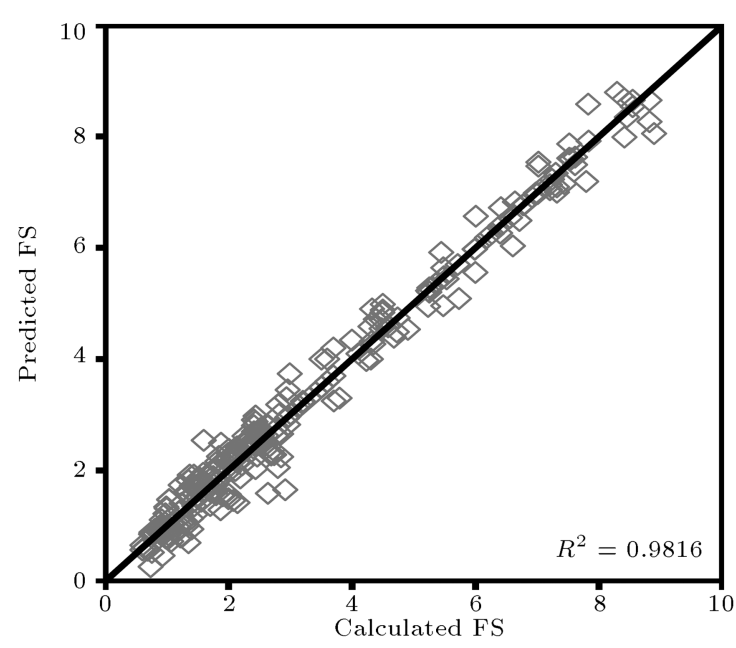

Figure 2. The comparison of the calculated FS values with the predicted FS values obtained from the ANN model for training samples.

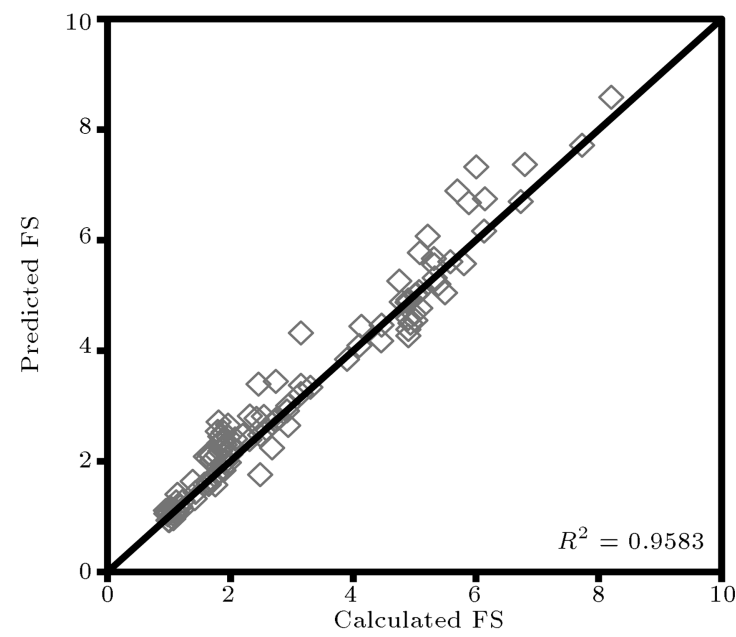

Figure 3. The comparison of the calculated FS values with the predicted FS values obtained from the ANN model for testing samples.

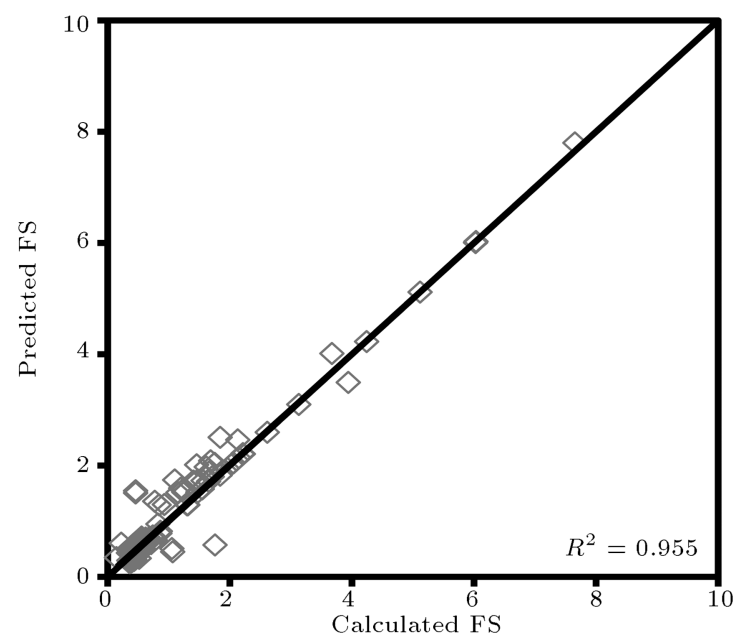

Figure 4. The comparison of the calculated FS values with the predicted FS values obtained from the ANN model for validation samples.

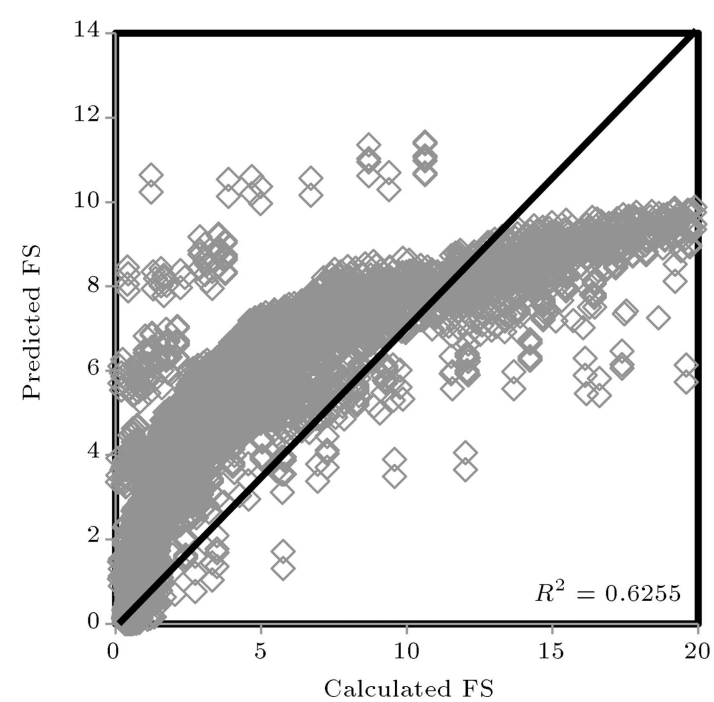

Figure 5. The comparison of the calculated FS values with the predicted FS values obtained from the MR model for all samples.

According to the results of the MR analysis, MR equation (Eq. (10)) has $R^{2}$ value of 0.626 . In addition, in order to examine the prediction capacity of MR model, the relationship between FS values predicted through Eq. (10) and those calculated by the simplified method [2] was examined for all samples, as shown in Figure 5. This figure illustrates that the MR model is not able to predict FS values accurately.

Additionally, four different performance indices, (the determination coefficient $\left(R^{2}\right)$, Variance Accounted For (VAF), Mean Absolute Error (MAE), and Root Mean Square Error (RMSE), given by Eqs. (12) to (15), respectively), were used to evaluate the predictability of the models. These calculated indices are listed in Table 4.

$$
\begin{aligned}
& R^{2}=1-\frac{\sum_{i=1}^{N}\left(y_{i}-\hat{y}_{i}\right)^{2}}{\sum_{i=1}^{N}\left(y_{i}-\bar{y}\right)^{2}}, \\
& V A F=\left[1-\frac{\operatorname{var}(y-\hat{y})}{\operatorname{var}(y)}\right] \times 100, \\
& M A E=\frac{1}{N} \sum_{i=1}^{N}\left|\left(y_{i}-\hat{y}_{i}\right)\right|, \\
& R M S E=\sqrt{\frac{1}{N} \sum_{i=1}^{N}\left(y_{i}-\hat{y}_{i}\right)^{2}},
\end{aligned}
$$

where var demonstrates the variance, and the measured and the predicted values are denoted by $y$ and $\hat{y}$, respectively.

In addition to the performance indices, to examine the models' predictabilities, a Scaled Percent Error (SPE) [30-35] versus cumulative frequency is plotted in Figures 6 and 7, respectively. 
Table 4. Performance indices $\left(R^{2}\right.$, RMSE, MAE, and VAF) of the ANN and MR models developed.

\begin{tabular}{clcccc}
\hline Model & \multicolumn{1}{c}{ Data } & $\boldsymbol{R}^{\mathbf{2}}(\boldsymbol{\%})$ & MAE & RMSE & VAF (\%) \\
\hline \multirow{2}{*}{ ANN } & Training set & 98.16 & 0.31 & 0.53 & 98.87 \\
& Validation set & 95.50 & 0.38 & 0.75 & 95.83 \\
& Testing set & 95.83 & 0.28 & 0.56 & 96.88 \\
& & & & & \\
MR & All set & 62.55 & 1.64 & 2.35 & 62.58 \\
\hline
\end{tabular}

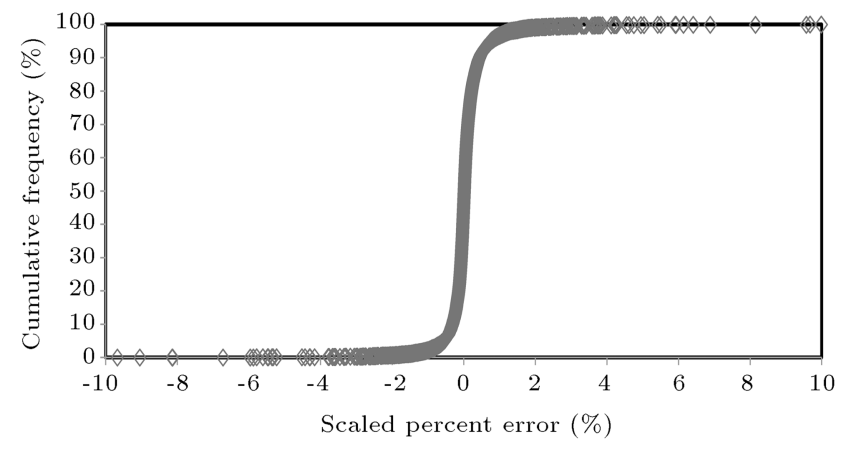

Figure 6. Scaled percent error of FS values obtained from the ANN model.

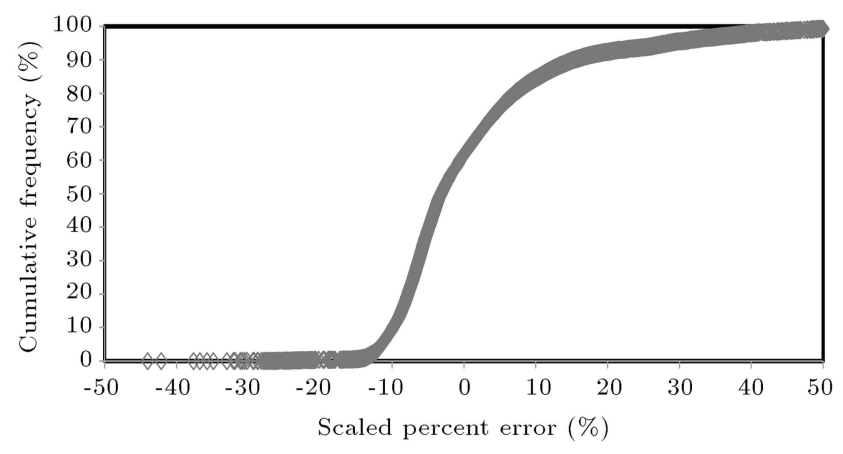

Figure 7. Scaled percent error of FS obtained from the MR model.

$$
S P E=\frac{\left(F S_{p}-F S_{c}\right)}{\left(\left(F S_{c}\right)_{\max }-\left(F S_{c}\right)_{\min }\right)},
$$

where subscripts $p$ and $c$ denote the predicted and computed FS values; subscripts max and min denote the maximum and minimum FS values. It can be observed that about $95 \%$ of the predicted FS value is in the $\pm 2 \%$ range of the SPE values, yielding an excellent estimation of the FS value. It can be noticed that about $87 \%$ of FS value predicted by the MR model is in the range of $\pm 15 \%$ of the SPE, giving a poor estimation of the FS value. These results indicate that the developed ANN model is superior to the MR model in predicting the FS value. It can be noted that the developed ANN model can be utilized to estimate the FS value for the liquefaction prediction and assessment.

As mentioned earlier, Figures 2 to 4 show the results of the FS values obtained by the ANN model compared with those computed by Seed and Idriss [2]

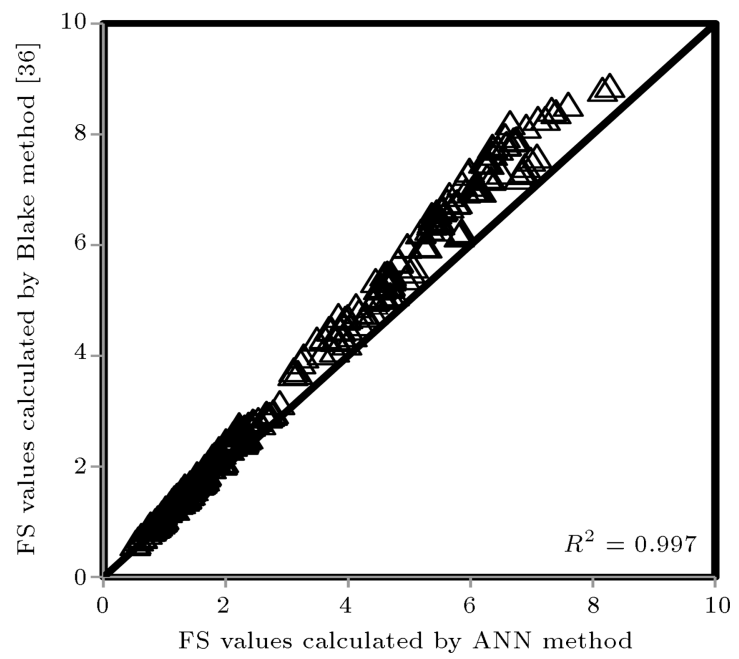

Figure 8. Comparison of the FS values predicted by ANN method and Blake method [36].

method, called the simplified method. The simplified method [2] is the most widely method for calculating FS values; however, this method includes performing many manual works requiring the use of tables or charts. Therefore, considering the ANN model's accuracy, the model can be utilized in the preliminary planning stage of the FS value without the need for performing any manual work mentioned above. Additionally, the FS values calculated by the other two SPT-based methods suggested by Blake [36] and Idriss and Boulanger [37] versus those obtained by ANN model are shown in Figures 8 and 9, respectively. These figures illustrate that the FS values calculated by both Blake [36] and Idriss and Boulanger [37] methods are found to be mostly greater than the FS values predicted by the ANN model, demonstrating a less secure estimation of liquefaction assessment for the SPT-based methods suggested by Blake [36] and Idriss and Boulanger [37].

\section{Conclusions}

In this study, the efficiency of the ANN and MR models in predicting the (FS) value was investigated. To this end, the FS values were computed by the use of the simplified method [2] through changing the soil and earthquake parameters, and this method was used 


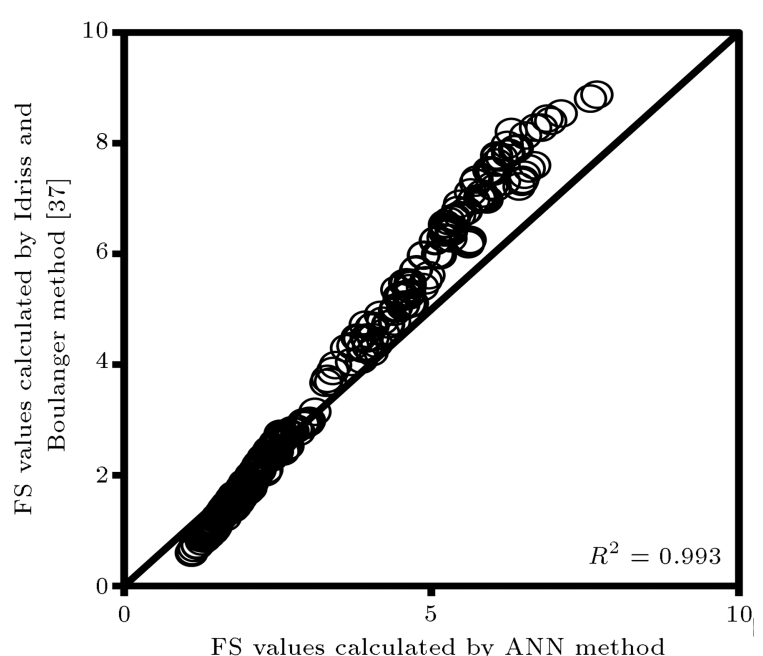

Figure 9. Comparison of the FS values predicted by ANN method versus Idriss and Boulanger method [37].

while developing both models. Six soil properties, namely standard penetration test number (SPT-N), Fines Content (FC), the depth of Ground Water Level (GWL), the depth of the soil $(d)$, saturated unit weight $\left(\gamma_{\text {sat }}\right)$, and natural unit weight $\left(\gamma_{n}\right)$ of soil, and two earthquake parameters, namely earthquake magnitude $\left(M_{w}\right)$ and horizontal peak ground acceleration $\left(a_{\max }\right)$, were used as input parameters in both models. The output parameter in both models was the calculated FS value. When the predicted $\mathrm{FS}$ values of both models were compared with the calculated FS values, it was found that the ANN model yielded FS values that are much more close to the computed FS values than MR model. In addition, five different performance indices were used to evaluate the predictabilities of the models developed. These performance indices indicated that the ANN models were superior to the MR model. Therefore, in the preliminary designing stage of the Factor of Safety (FS) against liquefaction, the ANN model developed in this study could be used accurately in the preliminary designing stage of the Factor of Safety (FS) against liquefaction without the need for performing any manual work such as the use of tables or charts.

\section{References}

1. Ishihara, K., Lysmer, J., Yasuda, S., and Hirao, H. "Prediction of liquefaction in sand deposits during earthquakes", Soils. Found, 16(1), pp. 1-16 (1976).

2. Seed, H.B. and Idriss, I.M. "Simplied procedure for evaluating soil liquefaction potential", J Soil. Mech. Found. Div., ASCE, 97(9), pp. 1249-1273 (1971).

3. Farrokhzad, F., Choobasti, A.J., and Barari, A. "Liquefaction microzonation of Babool city using artificial neural network", J. King. Saud. Univ. Sci., 24(1), pp. 89-100 (2012).
4. Youd, T.L. and Idriss, I.M. "Liquefaction resistance of soils: Summary report from the 1996 NCEER and 1998 NCEER/NSF workshops on evaluation of liquefaction resistance of soils", J. Geotech. and Geoenvir. Engrg., ASCE, 127(10), pp. 817-833 (2001).

5. Dixit, J., Dewaikar, D.M., and Jangid, R.S. "Assessment of liquefaction potential index for Mumbai city", Nat. Hazards Earth Syst. Sci., 12, pp. 2759-2768 (2012).

6. Tuskan, Y. "The use of neural networks in geotechnical engineering", MSc. Thesis, Celal Bayar University Manisa (In Turkish) (2012).

7. Shahin, M.A., Jaksa, M.B., and Maier, H.R. "Artificial neural network applications in geotechnical engineering", Aust. Geomech., 36(1), pp. 49-62 (2001).

8. Haykin, S., Neural Networks: A Comprehensive Foundation, Macmillan College Publishing Company, New York, USA (1994).

9. Choobbasti, A.J., Farrokhzad, F., and Barari, A. "Prediction of slope stability using artificial neural network (a case study: Noabad, Mazandaran, Iran)", Arab. J. Sci. Eng., 2, pp. 311-319 (2009).

10. Shi, J., Ortigao, J.A.R., and Bai, J. "Modular neural networks for predicting settlement during tunneling", J. Geotech. Geoenviron., 124(5), pp. 389-395 (1998).

11. Goh, A.T.C. "Seismic liquefaction potential assessed by neural networks", J. Geotech. Geoenv, 120(9), pp. 1467-1480 (1994).

12. Erzin, Y., Rao, B. H., and Singh, D.N. "Artificial neural networks for predicting soil thermal resistivity", Int. J. Therm. Sci., 47, pp. 1347-1358 (2008).

13. Guo, Z. and Uhrig, R.E. "Use of artificial neural networks to analyze nuclear power plant performance", Nucl. Technol., 99, pp. 36-42 (1992).

14. Amezquita-Sanchez, J.P., Valtierra-Rodriguez, M., Aldwaik, M., and Adeli, H. "Neurocomputing in civil infrastructure", Sci. Iran., 23(6), pp. 2417-2428 (2016).

15. Opan, M. "Determination of the pollution control flow for drought management in a multi-reservoir system", Sci. Iran., 23(6), pp. 2528-2535 (2016).

16. Özel, C. and Topsakal, A. "Comparison of ANFIS and ANN for estimation of thermal conductivity coefficients of construction materials", Sci. Iran., 22(6), pp. 2001-2011 (2016).

17. Jeng, D.S., Cha, D.H., and Blumenstein, M. "Application of neural network in civil engineering problems", Proceedings of the International Conference on Advances in the Internet, Processing, Systems and Interdisciplinary Research (2003).

18. Youd, T.L. and Noble, S.K. "Magnitude scaling factors", Proc., NCEER Workshop on Evaluation of Liquefaction Resistance of Soils, Nat. Ctr. for Earthq. Engrg. Res., State Univ. of New York at Buffalo, pp. 149-165 (1997). 
19. Seed, H.B., Tokimatsu, K., Harder, L.F., and Chung, R.M. "Influence of SPT procedures in soil liquefaction resistance evaluations", J. Geotech. Engrg., ASCE, 111(12), pp. 1425-1445 (1985).

20. Idriss, I.M. and Boulanger, R.W. "Semi empirical procedures for evaluating liquefaction potential during earthquakes", The 3rd Int. Conf. on Earthq. Geotech. Engrg. (ICEGE), pp. 32-56 (2004).

21. Liao, S.C. and Whitman, R.V. "Overburden correction factors for SPT in sand", J. Geotech. Eng., ASCE, 112(3), pp. 373-377 (1986).

22. Skempton, A.W. "Standard penetration test procedures and the effects in sands of overburden pressure, relative density, particle size, aging and overconsolidation", Geotech., 36(3), pp. 425-447 (1986).

23. Robertson, P.K. and Wride, C.E. "Evaluating cyclic liquefaction potential using the cone penetration test", Can. Geotech. J., 35, pp. 442-459 (1998).

24. Kayen, R.E., Mitchell, J.K., Seed, H.B., Lodge, A., Nishio, S., and Coutinho, R. "Evaluation of SPT, CPT, and shear wave-based methods for liquefaction potential assessment using Loma Prieta data", U.S. National Center for Earthquake Engineering Research (NCEER), New York, pp. 177-204 (1992).

25. Seed, H.B. and Idriss, I.M. Ground Motions and Soil Liquefaction During Earthquakes, Earthq. Engrg. Res. Inst. Mon., Oakland, Calif. (1982).

26. Youd, T.L. and Idriss, I.M. "Summary report", Proceedings of the NCEER Workshop on Evaluation of Liquefaction Resistance of Soils, NCEER-97-0022, December 31 (1997)

27. National Research Council (U.S.)., Liquefaction of Soils During Earthquakes, Committee on Earthquake National Academy Press, pp. 1-7 (1985).

28. Ishihara, K. "Stability of natural deposits during earthquakes" , 11th Int. Conf. on Soil. Mech. and Found. Engrg., A.A. Balkema, Rotterdam (1985).

29. Shahin, M.A., Jaksa, M.B., and Maier, H.R., Recent Advances and Future Challenges for Artificial Neural System in Geotechnical Engineering Applications, University of Adelaide (2008).

30. Kanibir, A., Ulusay, R., and Aydan, O., LiquefactionInduced Ground Deformations on a Lake Shore (Turkey) and Empirical Equations for Their Prediction, IAEG 2006, Paper 362 (2006).

31. Erzin, Y., Patel, A., Singh, D.N., Tiga, M.G., Yılmaz, I., and Srinivas, K. "Investigations on factors influencing the crushing strength of some Aegean sands", Bull. Eng. Geol Environ, 71, pp. 529-536 (2012).
32. Thaker, T.P. and Rao, K.S. "Development of statistical correlations between shear wave velocity and penetration resistance using MASW technique", PanAm CGS Geotech Con. (2011).

33. Erzin, Y. and Cetin, T. "The use of neural networks for the prediction of the critical factor of safety of an artificial slope subjected to earthquake forces", Scientia Iranica, 19(2), pp. 188-194 (2012).

34. Erzin, Y. and Gul, T.O. "The use of neural networks for the prediction of the settlement of one-way footings on cohesionless soils based on standard penetration test", Neural Comput and Applic, 24, p. 891 (2014).

35. Erzin, Y. and Cetin, T. "The prediction of the critical factor of safety of homogeneous finite slopes using neural networks and multiple regressions", Comput. and Geosci, 51, pp. 305-313 (2013).

36. Blake, T.F. "Summary report of proceedings of the NCEER workshop on evaluation of liquefaction resistance of soils", Youd T.L., and Idriss I.M., Eds., Technical Report, NCEER 97-0022 (1997).

37. Idriss, I.M. and Boulanger, R.W. "Semi-empirical procedures for evaluating liquefaction potential during earthquakes", Invited paper, 11th Intl. Conf. on Soil Dyn. and Eq. Eng. and 3rd Intl. Conf. on Eq. Geotech. Eng., Jan. 7-9, Berkeley, CA, pp. 32-56 (2004).

\section{Biographies}

Yusuf Erzin is an Associate Professor at the Department of Civil Engineering at Manisa Celal Bayar University, Manisa, Turkey. He received his BS degree in Civil Engineering from Selçuk University, Konya, Turkey, and his MS and PhD degrees in Civil Engineering from Middle East Technical University, Ankara, Turkey. His research interests include artificial neural networks, swelling soils, slope stability, and crushing strength of sands. He has published more than 25 papers in many International journals.

Yesim Tuskan is a Research Assistant at the Department of Civil Engineering at Manisa Celal Bayar University, Manisa, Turkey. She received BS and MS degrees in Civil Engineering from Manisa Celal Bayar University, Manisa, Turkey. She is currently a PhD student in the same university. Her research interests include computer programming, artificial neural networks, and slope stability. 